EESTI NSV TEADUSTE AKADEEMIA TOIMETISED, 31. KOIDE FOOSIKA * MATEMAATIKA, 1982, NR. 2

ИЗВЕСТИЯ АКАДЕМИИ НАУК ЭСТОНСКОИ ССР. ТОМ 31 ФИЗИКА * МАТЕМАТИКА, 1982, № 2

А. Ю. БОРИСОВ, Р. А. ГАДОНАС, Р. В. ДАНЕЛЮС, A. С. ПИСКАРСКАС, А. П. РАЗЖИВИН

\title{
КИНЕТИКА И МЕХАНИЗМЫ МИГРАЦИИ ЭНЕРГИИ ПРИ ФОТОСИНТЕЗЕ
}

Природный фотосинтез прямо или косвенно снабжает энергией все живое на Земле. С ним в квазиравновесии по $\mathrm{O}_{2}, \mathrm{CO}_{2}, \mathrm{P}, \mathrm{N}$ и другим соединениям и элементам находится весь живой мир. Каковы же его глобальные характеристики?

За год на Землю поступает солнечная радиация с энергией $\sim 3 \cdot 10^{24}$ Дж. Для сравнения отметим, что энергия всех земных полезных ископаемых (газ, нефть, уголь, уран) оценивается как $2-3 \cdot 10^{22}$ Дж. Это энергия солнечной радиации, приходящая на Землю всего лишь за неделю. Благодаря фотосинтезу биомасса всей планеты запасает за год примерно $3 \cdot 10^{21}$ Дж. Это лишь $0,1 \%$ от энергии солнечной радиации, но, с другой стороны. в 10 раз больше той энергии, которая использована человечеством в 1970 году [1,2].

В природных условиях у наиболее перспективных пастений эффективность запасания солнечной энергии не превышает $1 \%$, а в специальных реакторах, где суспензия водорослей постоянно перемешивается, эта эффективность достигает $3-5 \%$. Поэтому изучение этого фундаментального природного процесса приобретает теперь, на фоне углубляющегося энергетического кризиса, все большую актуальность.

За последнее десятилетие благодаря ярким успехам биохимии и биофизики сложились довольно четкие представления об организации энергопреобразующего аппарата фотосинтеза. Из фотосинтезирующих бактерий, водорослей и растений удалось выделить мельчайшие, размерами всего лишь в деслтки-тысячи ангстрем, хлорофилл-белковые комплексы и фрагменты белково-липидных мембран, которые сохраняют способность преобразовывать световую энергию в электрохимическую. Это было засвидетельствовано специально разработанными оптическими дифференциальными спектрофотометрами. С их помощью было показано, что в выделяемых биохимическими методами фрагментах (напр., в хроматофорах из пурпурных бактерий) на свету по различным сторонам белково-липидной мембраны накапливаются сильно восстановленные хиноны и окисленные иंоны, т. е. возникает свободная электрохимическая энергия или, иначе, некий фотоаккумулятор. Спектры действия четко показали, что активным для этого фотоэффекта является свет, поглощаемый хлорофиллами. Естественно, встал вопрос о механизмах преобразования солнечной энергии и о трехмерной молекулярной архитектуре соответствующего аппарата.

K настоящему времени установлены следующие факты:

1. Фотоэлектрический аппарат локализован в тонких белково-липидных мембранах фотосинтезирующих организмов. Локальная концентрация хлорофиллов и сопровождающих пигментов в них доходит до долей моля. На пигменты приходится порядка $10 \%$ веса биомембран.

2. Молекулы хлорофиллов встроены в белковые глобулы биомембран скорее хаотично, чем упорядоченно. 
3. Фотоэлектрическое преобразование порожденных светом электронно-возбужденных состояний (ЭВС) в хлорофилле происходит в специализированных хлорофилл-белковых комплексах - т. н. реакционных центрах (РЦ), которые обычно имеют вес $\sim 50-100$ килодальтонов и включают в себя четыре молекулы хлорофилла и две молекулы его предшественника феофитина $\left[{ }^{3}\right]$.

4. В среднем на каждый РЦ приходится 100-300 молекул т. н. антенного хлорофилла, который лишь поглощает световую энергию $\left[{ }^{3}\right]$.

5. Перенос энергии ЭВС от антенного хлорофилла на РЦ осуществляется в основном бестоковым механизмом индуктивного резонанса.

6. Квантовый выход этой доставки энергии составляет для различных представителей мира фотосинтеза $80-95 \%\left[{ }^{2}\right]$.

Первым, кто экспериментально обосновал механизм индуктивного резонанса в фотосинтезе, был голландский биофизик Л. Н. М. Дёйсенс $\left[{ }^{4}\right]$. Однако в то время в литератvре по фотосинтезу бытовали неверные данные о времени жизни $Э В С\left(\tau_{\text {фл }}\right)$ в хлорофилле $\sim 10^{-8} c$, что привело ряд авторов к обоснованию медленного, индуктивного резонанса при фотосинтезе. Первые экспериментальные данные, полученные в 60 -х годах рядом лабораторий мира методом фазовой флуорометрии, дали значения $\tau_{\text {фл }} \sim 1-2$ нс (см. обзор $\left.\left[{ }^{2}\right]\right)$. Однако наши последующие работы $\left[{ }^{5,6}\right]$ показали, что эти времена ассоциируются с небольшими фракциями хлорофиллов, утерявшими связь с фотосинтетическими процессами. С помощью специально разработанного метода временного рычага нами было установлено [6], что у основной массы антенного хлорофилла $\tau_{\text {фл }}$ по крайней мере в 15 раз меньше, чем ранее измеренные, - не более 30-100 nc. Следовательно, если на один РЦ приходится около 100 молекул антенного хлорофилла, то для доставки кванта ЭВС на РЦ требуется не менее 100 актов миграции и время одного акта миграции составляет не более $0,3-1,0$ nc $\left[^{5-8}\right]$ (подробнее этот вопрос рассмотрен в $\left.\left[{ }^{2,7}\right]\right)$.

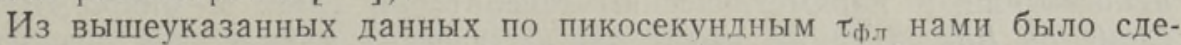
лано несколько принципиальных выводов: а) квантовый выход доставки ЭВС на РЦ высок потому, что время доставки $(\not 100$ nc) существенно короче, чем время тривиальных процессов дезактивации ЭВС в антенном хлорофилле в тепло, флуоресценцию и тvшение на паразитных центрах и ассоциатах хлорофиллов $\left(\sim 10^{-9} c\right)$; б) квантовый выход заселения триплетных уровней антенного хлорофилла не превышает нескольких процентов, так как in vivo не имеется факторов, способных увеличить константу интеркомбинашионной конверсии, которая у различных хлорофиллов бывает порядка $10^{8} c^{-1}\left[{ }^{5}\right]$; в) столь короткая активация хлорофилла светом исключает возможность осуществления первичной реакции фотосинтеза механизмом лимитируемой диффузией химической реакции; г) субпикосекундные времена актов миграции по антенному хлорофиллу свидетельствуют о том, что доставка энергии на РЦ осуществляется экситонным механизмом индуктивного резонанса при умеренном диполь-дипольном взаимодействии молекул, оцененном нами как $10^{-2}$ э $B\left[{ }^{5,6,2}\right]$. Однако все эти выводы базировались на наших данных, полученных с помощью модифицированной техники фазовой флуорометрии. Несомненно, они нуждались в серєезной проверке более прямыми и информативными методами.

Такая возможность возникла с появлением пикосекундных лазеров и соответствующей техники обработки и регистрации пикосекундных процессов. Правда, первые флуорометрические исследования фотосинтезирующих объектов дали артефактные значения $\tau_{\text {Фл }}$ хлорофилла порядка 10-30 nc. Выяснилось, что адекватный задаче прибор должен обязательно работать в режиме одиночных импульсов с энергией, не

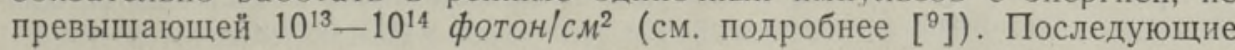


корректные измерения дали значения $\tau_{\phi л} \sim 100 n c\left[^{10-12}\right]$ (см. обзоры $[13,14])$.

В 1973 году начались параллельные исследования фотосинтезирующих объектов методом пикосекундной абсорбционной спектроскопии [ $\left.{ }^{15}\right]$. Әтот метод, в отличие от флуоресцентного, которым могли исследоваться лишь наиболее сильно флуоресцирующие фракции хлорофиллов, оказался значительно информативнее. В частности, именно с его помощью была впервые выявлена кинетика первичной конверсии ЭВС в РЦ пурпурных бактерий $\left[{ }^{16-18}\right]$. В этих же работах было открыто короткоживущее состояние $P^{F}$, которое за 120 - 250 nc превращалось в относительно стабильное (до секунд) состояние с разделением разноименных зарядов по различные стороны белковой глобулы РЦ $\left[{ }^{16,17}\right]$. Но все эти работы приходилось выполнять на препаратах РЦ, экстрагированных биохимиками из биомембран и лишенных тем самым всей антенной фракции хлорофилла. Работа же на нативных биомембранах требовала существенного повышения чувствительности приборов вплоть до $10^{-3}-10^{-4}$ ед. оптической плотности при собственном поглощении объекта порядка 0,5 ед. Реализация в нашем приборе режима дифференциального спектрофотометра позволила. впервые поставить пикосекундные абсорбционные эксперименты на нативных биомембранах - хроматофорах из пурпурной фотобактерии Rh. rubrum. Ниже как пример приводятся результаты опытов, выявивших в антенне этих частиц небольшую фракцию хлорофилла В905, фокусирующую ЭВС из антенны на РЦ.

\section{Методы}

Эксперименты проводились на многоцелевом пикосекундном спектрометре, созданном на кафедре астрономии и квантовой электроники Вильнюсского государственного университета (ВГУ) $\left[{ }^{19}\right]$. Он оснащен пикосекундным параметрическим генератором света и микро-ЭВМ в схеме on line, а также имеет два оптических канала, что позволило впервые реализовать дифференциальный спектрофотометр с пикосекундным временным разрешением и применить его для исследования фотосинтезирующих объектов. Перечислим основные принципиальные особенности прибора: 1) из пикосекундного цуга выделяется один импульс; 2) оптический диапазон перекрывается от 400 до 1500 нм; 3) при накоплении до 120 импульсов на каждой длине волны или в каждой точке кинетики чувствительность по изменениям абсорбции достигает $2 \cdot 10^{-4}$ ед. оптической плотности; 4) благодаря автоматизации эксперимента значительно ускоряется получение заданного массива

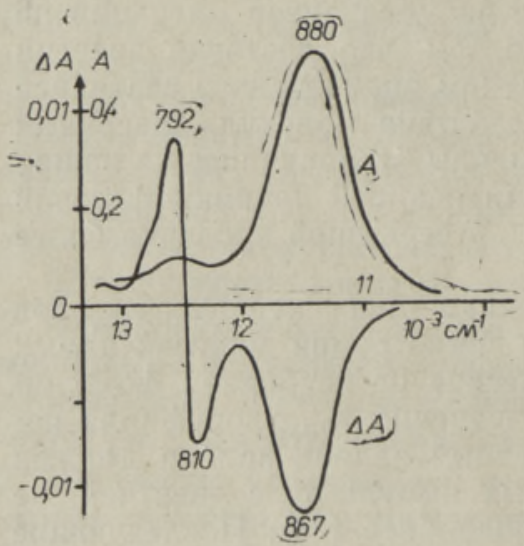

Рис. 1. $A-$ Спектр поглощения суспензии хроматофоров, выделенных из пурпурной фотобактерии $R h$. rubrum. Полосы при 880 и 800 нм принадлежат переходу $S_{0} \rightarrow S_{1}$ соответственно для антенного хлорофилла и небольшой фракции хлорофилла реакцнонного центра - $\mathrm{P} 800 . \Delta \mathrm{A}-$ Разностный спектр «свет минус темнота», полученный для того же препарата на дифференциальном спектрофотометре, где две идентичные кюветы с суспензией хроматофоров помещались в оба оптических канала прибора и затем один из них освещался постоянным, насыщающнм фотосинтез светом, 


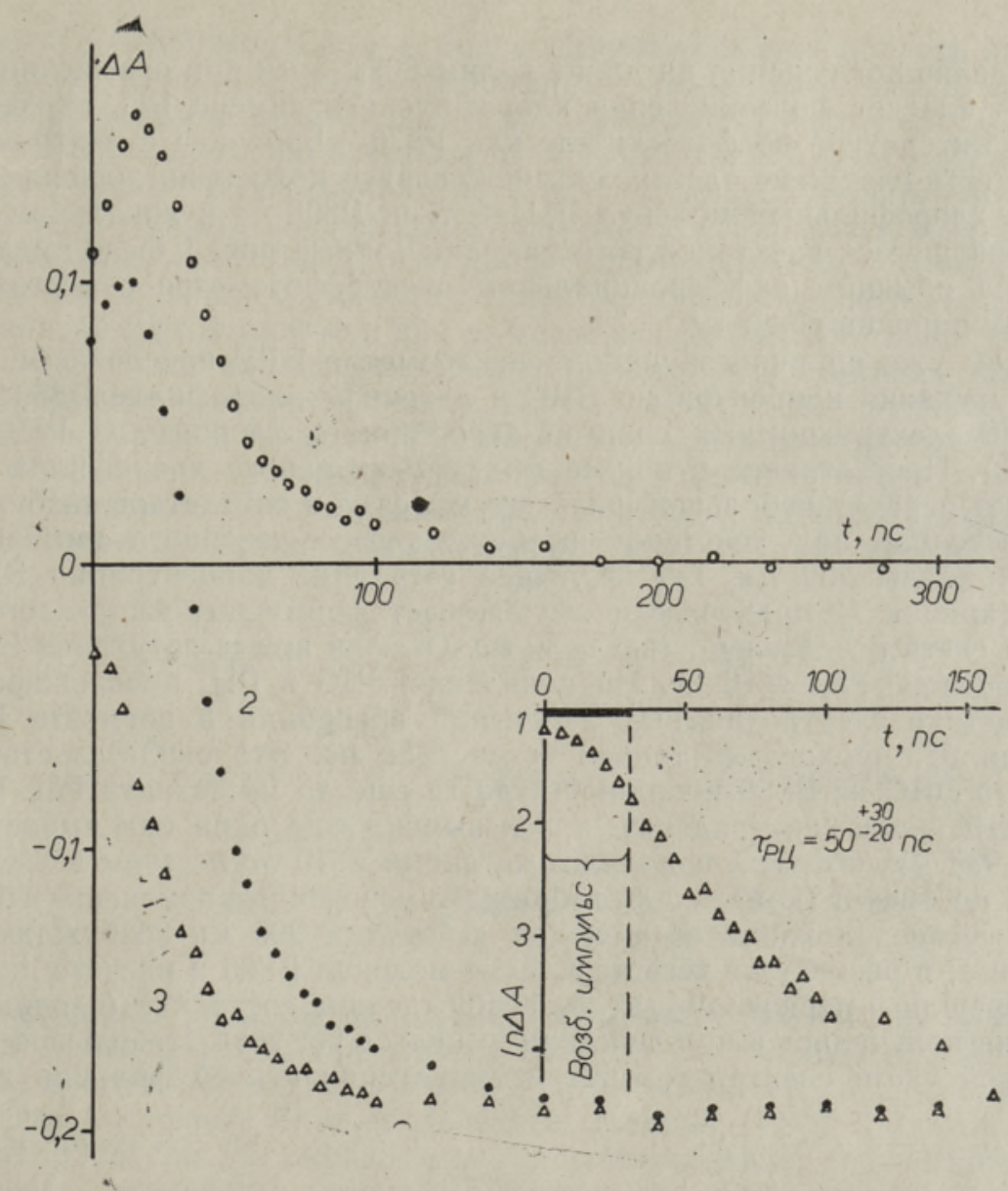

Рис. 2. Кинетика пикосекундных изменений абсорбции суспензии хроматофоров $R h$. rubrum под действием пикосекундного возбуждающего импульса с длиной волны 900 нм. Оптическая плотность образца при 900 нм составляла 0,4 ед. Длительность импульса $30 \mathrm{nc}$, энергия порядка $3 \cdot 10^{3}$ фотон.см ${ }^{-2}$ на засвечнваемой площади кюветы, равной примерно $2 \mathrm{Mм}^{2}$. Накопление по 120 импульсов в каждой точке. Кривая 1 - кинетика исчезновения электронных возбужденных состояний антенного хлорофилла В880, снятая по поглощению этих молекул $S_{1} \rightarrow S_{n}$ при $800 \mathrm{~m}$, тде электрохромные изменения абсорбции пигмента РЦ Р800 отсутствуют; кривая 2 - суммарная кинетика исчезновения электронных возбужденных состояний антенного хлорофилла и электрохромных изменений абсорбции пигмента Р800 в РЦ, зарегистрированная при 810 нм; кривая 3 - получена вычитанием кривой 1 из кривой 2 и построена в линейном и логарифмическом (на вставке) масштабах.

информации, что очень важно при изучении недостаточно стабильных биообъектов.

Такие характеристики прибора позволили впервые провести исследования быстрой миграции энергии по хлорофильной антенне и внутри РЦ у фотосинтезирующих бактерий $\left[{ }^{19-21}\right]$.

\section{Экспериментальные данные и их обсуждение}

В спектре поглощения суспензии хроматофоров из Rh. rubrum доминирует полоса абсорбции при 880 нм антенного хлорофилла (рис. 1). 
Уменьшение поглощения на длине волны $867 \pm 3$ нм при освещении происходит за счет фотоокисления хлорофильного димера РЦ, обозначаемого в литературе по фотосинтезу как Р870. «Бабочка» с центром при 800 нм есть следствие электрохромного сдвига полосы поглощения двух других хлорофильных молекул РЦ - т. н. Р800 - в локальном поле образовавшегося электрического диполя. Данные рис. 1 были получены нами на обычном дифференциальном спектрофотометре с постоянной времени порядка секунды.

Затем уже на пикосекундном спектрометре ВГУ прослежены кинетика затухания концентрации ЭВС в антенном хлорофилле В880 и появление электрохромных сдвигов абсорбции в хлорофилле РЦ Р800 (рис. 2). Просветление в полосе фракции антенного хлорофилла В880 означает переход небольшой доли его молекул в синглетное возбужденное состояние под действием возбуждающего лазерного импульса с длиной волны 900 нм. Последующее затухание концентрации ЭВС в B880 (кривая 1) практически отслеживает форму возбуждающего импульса света с длительностью $\simeq 30 n c$. Отсюда время затухания ЭВС в В880 оценено как $₹ 10$ nc. Но появление ЭВС в РЦ, прослеживаемое по кинетике электрохромных изменений абсорбции в пигменте Р800* (кривая 3 ), происходит только через $\simeq 50$ nc. Это свидетельствует о том, что ӘВС из В880 попадают куда-то еще до их захвата РЦ. Предпринятый нами спектральный поиск выявил еще один пик выцветания около 905 нм, который появлялся за время $₹ 10$ nc и затем исчезал за $60 \pm 15 n c$. Рис. 3 (кривая А) отображает мгновенные изменения абсорбции в суспензии хроматофоров под действием $900 \mathrm{\mu м}$ возбуждающего импульса, в результате чего несколько молекул В 880 в расчете на один РЦ перешли в первое синглетное возбужденное состояние (сходные изменения получались и при действии импульса 532 нм). Небольшое плечо в правой части спектра говорит о выцветании некоей фракции хлоро-

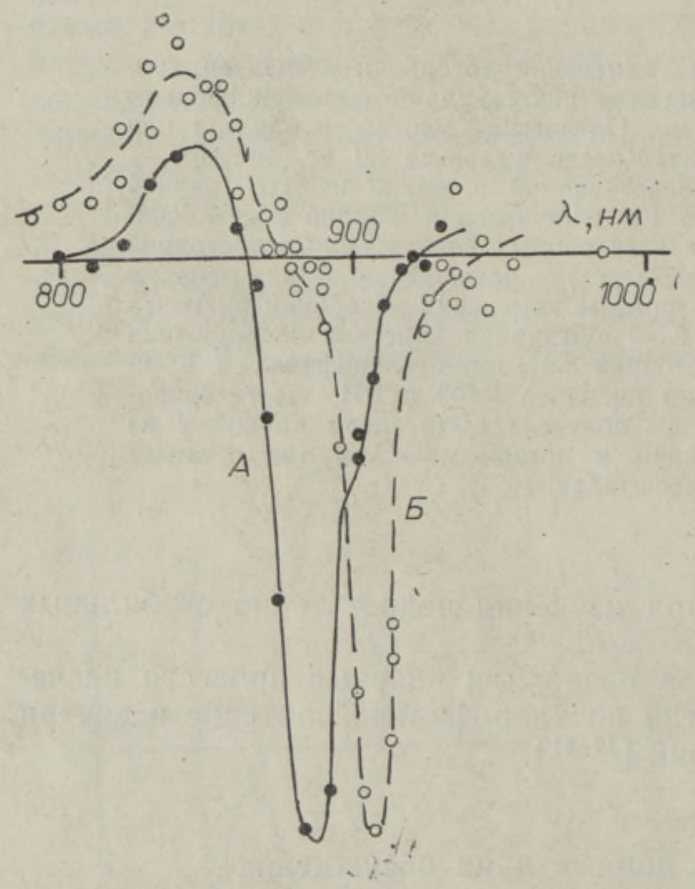

Рис. 3. Спектры пикосекундных изменений абсорбции под действием возбуждающих импульсов (все данные, как на рис. 2). А - Спектр снят при низкой интенсивности возбуждающих импульсов (менее $10^{15}$ фотон.СM-2), совпадающих по времени с зондирующими импульсами. Б - Спектр снят также при нулевой задержке зондирующих импульсов относительно вөзбуждающих, но при высокой интенсивности последних (более $10^{17}$ фотон.см ${ }^{-2}$ ).

* Наблюдать нзменения в основной полосе димера РЦ при 867 нм затрудняет наложение эффектов выцветания полос В880* и В905*. 
филла с $S_{0} \rightarrow S_{1}{ }^{*}$-переходом в более длинноволновую об̆ласть спектра̀. Эта гипотетическая фракция хлорофилла четко выявлялась в спектре, снятом при низкой интенсивности возбуждающего импульса. При этом ЭВС в В880 полностью исчезали и оставалось лишь выцстание около 905 нм (кривая Б, по амплитуде ссотзетст-уощая возбуждению примерно $4 \pm 1$ молекул хлорофилла). Впрочем, с этим выводом не следует спешить, поскольку попадание сразу нескольких ӘВС в небольшую группу молекул может вызывать в ней различные нелинейные взаимодействия. С другой стороны, при сильном взаимодействии молекул даже одно ЭВС в них, по-видимому, может приводить к сильному выцветанию абсорбции в основной полосе. По-видимому, такая группа молекул находится рядом с каждым РЦ, поскольку времена затухания ЭВС в В905 и появление электрохромных сдвигов у Р800 в пределах погрешности совпадают. Поэтому нам представляется логичной следующая схема переноса энергии светоиндуцированных ӘВС от антенны к РЦ:

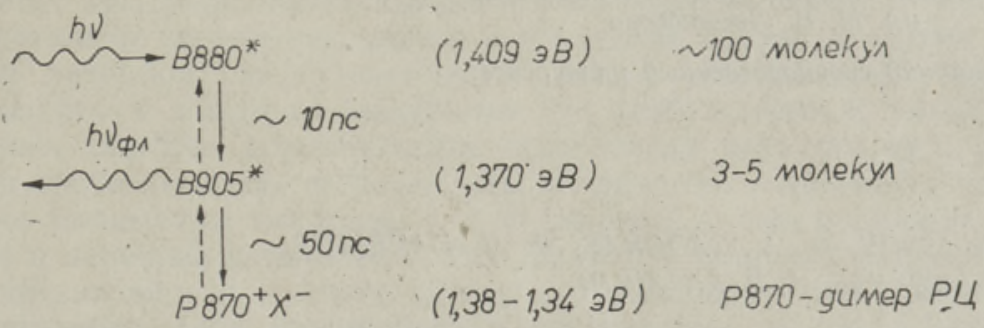

На фракцию В905 как на ловушку «скатываются» ЭВС из 100 антенных молекул В880, так как их энергии отличаются примерно на 40 мэB, а затем они захватываются РЦ, по-видимому, сразу же порождая в них состояние $P^{F}$ с разделением зарядов $\left(\mathrm{P} 870^{+} \mathrm{X}^{-}\right)$. Миграция ЭВС от В905* на РЦ, приводящая к возникновению синглетного возбужденного состояния димера Р870, представляется менге вероятной из-за энергетического барьера между ними порядка 55 мэВ. Наблюдаемая у хроматофоров $R h$. rubrum флуоресценция с максимумом при $915 \pm 5$ нм (по литературным данным) испускается, очевидно, фракцией В905, поскольку время жизни в ней ЭВС по крайней мере в несколько раз больше, чем в В880. По-видимому, часть этой флуоресценции является пикосекундным послесвечением за счет обращения процесса $\mathrm{P} 870+\mathrm{X}^{-} \mathrm{B} 905 \rightleftarrows \mathrm{P} 870 \mathrm{X}$ B905*.

\section{ЛИТЕРАТУРА}

1. Bolt on, J. R., Hall, D. O., Ann. Rev. Energy, 4, 353-401 (1979).

2. B or is ov, A. Yu., In: Topics in Photosynthesis (ed, J. Basber), 3, Elsevier, North Holland Biomedical Press, Amsterdam, 1979, p. 1-26.

3. Blankenship, R. E., Parson, W. W., the same as ref. 2, p. $71-114$.

4. Duy s en s, L. N. M., Thesis, Utrecht, 1952.

5. Бори сов А. Ю., Й льина М. Д., Бнохимия, 36, № 4, 822-825 (1971).

6. B or is ov, A. Yu., Godik, V. I., J. Bioenerget., 3, $211-220$ (1972).

7. Бо р и со в А. Ю., Молекуляр. биология, 12, вып. 2, 267-275 (1978).

8. Bor isov, A. Yu., God ik, V. I., Biochim. Biophys. Acta, 301, 227-248 (1973).

9. Campillo, A. J., Koll man, V. H., Shapiro, S. L., Science, 193, 227-229 (1976).

10. Campillo, A. J, Hyer, R. G., Monger, T. G., Parson, W. W., S ha piro, S. L., Proc. Nat. Acad. Sci. USA, 74, 1997-2001 (1977).

11. Searle, J. F., Barber, J., Harris, L., Porter, G., Tredwell, C. J., Biochim. Biophys. Acta, 459, 390-401 (1977).

12. Paschenko, V. Z.. Kononenko, A. A., Protasov, S. P., Rubin, A. B., Rubin, L. B., Uspenskaja, N. Y., Biochim. Biophys. Acta, 461, 403-414 (1977). 
13. Holt en, D., W indzor, M. W., Ann. Rev. Biophys. Bioeng., 7, 189-227 (1978).

14. Campillo, A. J., Shapiro, S. L., In: Topics in Applied Physics (ed. S. L. Shapiro), 18, Springer-Verlag, Berlin-Heide'berg-New York, 1977, p. $318-367$.

15. Netzel, T. L., Rentzepis, P. M., Le igh, J. S., Science, 182, 238-241 (1973).

16. Kaufman, K. J., Dutton, P. L., Netzel, T. L., Leigh, J. S., Rentz e p i s, P. M., Science, 188, 1301-1304 (1975).

17. Rockley, M. G., Windsor, M. W., Cogdell, R. J., Parson, W. W., Proc. Nat. Acad. Sci. USA, 72, 2251-2254 (1975).

18. Shuvalov, V. A., Klevanik, A. V., Sharkov, A. V., Matveetz, Yu. A., K r y u k ov, P. G., FEBS Lett., 91, 135-139 (1978).

19. Ахманов С. А., Борисов А. Ю., Козловский В. С., Разживин А. П., Данелюс Р. В., Пи ска рска с А. С., Биофизика, 23, $912-913$ (1978).

20. Akhmanov, S. A., B or isov, A. Yu., Danielius, R. V., Gadonas, R. A., Kozlovski, V. S., Piskarskas, A. S., Razjivin, A. P., Shuv a $10 \mathrm{v}, \mathrm{V}$. A., FEBS Lett., 114, 149-152 (1980).

21. Бор и сов А. Ю., Годик В. И.; Изв. АН СССР, сер. физ., 44, № 4, 738-744 (1980).

\section{Московский государственный университет} и.. М. В. Ломоносова

Вильнюсский государственный университет

A. J. BORISSOV, R. A. GADONAS, R. V.'DANELIUS,

A. S. PISKARSKAS, A. P. RAZZIVIN

\section{ENERGIAULEKANDE MEHHANISMID JA KINEETIKA FOTOSUNTEESIS}

Artiklis on antud ülevaade fotosünteesi primaarsete fotofüüsikaliste protsesside uurimisest optiliste pikosekundmeetoditega, vaade!dud elektronergastuse energia ülekannet valgust koguvalt antennklorofüllilt reaktsioonitsentritele ning kirjeldatud Vilniuse ülikooli 10 -20-ps-lise aeg!ahutusega laserspektromeetrit, millega esmakordselt uuriti energia. ülekannet purpurbakterite natiivsetes kromatofoorides.

A. YU. BORISOV, L. A. GADONAS, R. V. DANELIUS, A. S. PISKARSKAS, A. P. RAZZHIVIN

\section{KINETICS AND ENERGY MIGRATION IN PHOTOSYNTHESIS}

The optical picosecond studies of photosynthesis are reviewed briefly. The processes of migration of photoinduced electronic excitations from light-harvesting chlorophyllous «antenna» to energy-converting reaction centres are outlined. A multi-purpose picosecond laser spectrometer, developed in Vilnius State University, is introduced. The optical parametric oscillators employed in this instrument enabled a wide optical region from 450 to $4800 \mathrm{~nm}$ to be covered. The automatization of the experiment and computerprocessing of the running data from three optical channels increased the sensitivity up to $2 \cdot 10^{-4}$ o.d. units at a low energy in exciting and probing monopulses $\left(\gtrless 10^{12}-\right.$ $10^{14}$ photons) and the time resolution of $\approx 10-20 \mathrm{ps}$.

The instrument enab!ed us to investigate for the first time the intact chromatophores of purple bacteria. The kinetics of excitation migration from antenna chlorophylls to reaction centres were observed. A new small fraction of chlorophyll was discovered which focusses excitations from numerous antenna chlorophylls in the nearest proximity of the reaction centre. 